\title{
The relationship between bending and tension strength of Irish and UK spruce and pine
}

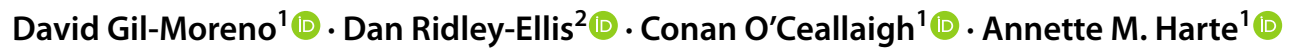

Received: 7 April 2021 / Accepted: 18 January 2022 / Published online: 7 February 2022

(c) The Author(s) 2022

\begin{abstract}
The correct characterisation of wood properties is fundamental for the best utilisation of resources. In Europe, grading is defined by strength classes that are determined based on either bending or tension tests. The European standards give equations to estimate characteristic strength in tension from characteristic strength in bending, and vice versa depending on which was tested. These equations are applied to all softwoods. The aim of this paper is to empirically determine the relationship between bending and tension strength properties using two conifer species grown in Ireland and the UK. The results show that the relationships change with species. The standard conversion underestimates, importantly, the performance of spruce for tension loads calculated for the most common bending strength class for Ireland and the UK, C16. The opposite occurs on the reverse conversion. Additionally, the study includes published data from continental Europe, to establish a new conversion that uses timber from a broader range of grades, and that adjusts the tension performance of Irish and UK spruce obtained from bending strength classes, ensuring safe values for design.
\end{abstract}

\section{List of symbols}

$\rho \quad$ Density used for grading, clear wood density

$E \quad$ Modulus of elasticity, in bending $\left(E_{m}\right)$ or tension $\left(E_{t}\right)$

$E_{d y n} \quad$ Dynamic modulus of elasticity

$f_{m, k} \quad$ Characteristic (fifth percentile) bending strength parallel to the grain

$f_{t, 0, k} \quad$ Characteristic (fifth percentile) tension strength parallel to the grain

$I P_{t} \quad$ Predicted tension strength, calculated in a multiple linear regression

$I P_{m} \quad$ Predicted bending strength, calculated in a multiple linear regression

TKAR Total knot area ratio

$B S \quad$ British spruce

$S P \quad$ Scots pine

David Gil-Moreno

david.gil-moreno@nuigalway.ie; dagilmo@gmail.com

1 School of Engineering and Ryan Institute, National University of Ireland Galway, Galway, Ireland

2 Centre for Wood Science and Technology, Edinburgh Napier University, Edinburgh, UK

\section{Introduction}

Sawn timber needs to be strength graded prior to its use for structural applications. In Europe, grading is based on the allocation of timber to groups called strength classes. These classes are defined by sets of statistical "characteristic values" of key properties, that allow safe design with timber by specifying minimum requirements for those values, allowing them to be used for structural calculations. For this, it is first necessary to derive relationships to predict the properties, so that the grading can correctly take place. Normally the three key wood properties investigated are bending stiffness $\left(E_{m}\right)$, bending strength $\left(f_{m}\right)$ and density $(\rho)$. The characteristic values for stiffness $\left(E_{m, 0, \text { mean }}\right)$ are based on the mean, whereas for strength $\left(f_{m, k}\right)$ and density $\left(\rho_{k}\right)$ it is based on the lower $5^{\text {th }}$ percentiles. Thus, it is the collective properties within a grade that matter, and not the properties of individual pieces of timber.

Even though grading established on the basis of bending tests is the most common method, in Europe strength grading can also be determined based on tension testing (Ridley-Ellis et al. 2016). Depending on the types of loads to which the timber will be subjected in service, one basis of grading will be more efficient than the other. While bending strength is the most common basis for grading in timber construction, tension properties are still important for elements like trusses and I-joists. Interest in mass timber 
construction in recent years has also raised the profile of tension-based strength classes of lamellas for glulam manufacturing. In fact, the most recent version of EN338 (CEN 2016a) includes strength classes for tension grading of softwoods ( $\mathrm{T}$ classes) in addition to the more familiar bending classes ( $\mathrm{C}$ classes), although tension classes had been in use for more than a decade previously. Irrespective of the testing basis being bending or tension, the strength classes are based on the characteristic values of stiffness, strength and density. While grading could conceivably be based on both tension and bending testing, the cost of this would be prohibitive. For economic and practical reasons, it is also common to use timber graded on the basis of bending in situations where tension is the dominating load. Moreover, it is often the case that bending elements need to be designed for tensile load, and vice versa. This is why the other strength property can be conservatively estimated by empirical relationships (EN 384) even though this can result in less efficient use of wood depending on the situation.

The grading process, whether done by machine or visually, uses non-destructive assessment of the wood that is indicative of the three grade determining properties. One kind of long-standing indicating property (IP) used to predict wood properties is knot indices, which is familiar for visual grading, but also, in a different form, part of grading by machines using principles such as X-rays, and optical mapping of the wood surface. In recent years, the use of non-destructive techniques based on the measurement of dynamic modulus of elasticity $\left(E_{d y n}\right)$ has also become broadly applied (Gil-Moreno et al. 2019b; Krajnc et al. 2019b; Ridley-Ellis et al. 2018) since it is relatively easy to apply and usually gives strong relationship with mechanical properties, even in logs and standing trees (Gil-Moreno and Ridley-Ellis 2015; Llana et al. 2020; Wang 2013). Knot index and $E_{d y n}$ are used in the current study as representative examples of IP, but there are also others in common use.

The empirical relationships in the standards can change when standards are revised, especially when there is new test data to inform safe, effective grading. This changes the design values for strength classes, and may need previously calculated designs to be changed in the case of reductions. The standard EN338:2009 provided Eq. (1) to determine characteristic tension strength parallel to the grain $\left(f_{t, 0, k}\right)$ based on characteristic bending strength $\left(f_{m, k}\right)$, but the 2016 revision (EN384:2016, EN338:2016) changed this to a new equation, Eq. (2), which (together with the rounding used in EN338) had the effect of reducing tension strength values below $\mathrm{C} 22$ and increasing them for higher grades. This revision also included the listing of softwood tension strength classes, and a corresponding equation, Eq. (3), for calculating the characteristic bending strength from the characteristic tension strength. Note that the equations are conservative estimates of one property based on test results of the other (derived using the lower 75\%-prediction line around the regression), and so Eq. (2) and Eq. (3) can only be applied in the direction as written.

$f_{t, 0, k}=0.6 f_{m, k}$

$f_{t, 0, k}=-3.07+0.73 f_{m, k}$

$f_{m, k}=3.66+1.213 f_{t, 0, k}$

The basis for the new equations was extensive test data on spruce and pine from the Gradewood project (Ranta-Maunus et al. 2011), summarised for the standards committee CEN TC124 WG2 in document N832, which used $E_{d y n}$ and the TKAR knot index (total knot area ratio) as representative IPs in the analysis. For balance, only Gradewood data from countries where both bending and tension tests were carried out were used. This comprised 429 bending tests and 423 tension tests for Scots pine (Pinus sylvestris L.), originating from Poland and Sweden, and 2615 bending tests and 1392 tension tests for Norway spruce (Picea abies L.) originating from Poland, Romania, Sweden, Slovenia, Slovakia and Ukraine.

Wood properties vary from species to species, and by country (Lavers 2002). In the $\mathrm{N} 832$ report, the $f_{m, k}$ values for each country ranged between 20 and $26 \mathrm{~N} / \mathrm{mm}^{2}$ (average $21.9 \mathrm{~N} / \mathrm{mm}^{2}$ ) for spruce, and $17-23 \mathrm{~N} / \mathrm{mm}^{2}$ (average $19.8 \mathrm{~N} / \mathrm{mm}^{2}$ ) for pine. It is common for spruce and pine from Scandinavia and Central Europe to achieve strength classes above C22 (Fischer et al. 2016, 2015; Hanhijärvi and Ranta-Maunus 2008; Høibø et al. 2013; Stöd et al. 2016). In Ireland and the UK, the main species grown for construction is Sitka spruce (Picea sitchensis (Bong) Carr.). The species is typically graded for structural timber to C16 $\left(E_{m, 0, \text { mean }}=8 \mathrm{kN} / \mathrm{mm}^{2}, f_{m, k}=16 \mathrm{~N} / \mathrm{mm}^{2}, \rho_{k}=310 \mathrm{~kg} / \mathrm{m}^{3}\right)$, but actually has superior strength and density than this requires. Grading is limited by the stiffness (Moore et al. 2013), a common feature in other species in the growing region (GilMoreno et al. 2016a). The lower performance compared to species growing in continental Europe is largely influenced by the shorter rotation lengths used. Typically these are 35-45 years (Moore 2011) but can be shorter (Ni Dhubháin et al. 2006). This limits the growth of the outerwood, which has higher mechanical properties (Kliger et al. 1998; Moore et al. 2012). Sitka spruce has similar properties to Norway spruce, and these are graded together as a species combination known as British spruce, recognised in the standards EN13556 and EN14081-1 (species code WPCS). Timber from Ireland and the UK is often graded using the same rules (Gil-Moreno et al. 2019b) due to the similar growing conditions that result in comparable timber characteristics. Scots pine is a native minor species, and although it can perform better than spruce, and achieve high yields of C20 (Moore 
et al. 2008; Fátharta et al. 2020), there is currently little information on the wood properties of the species grown in these countries. The current study covers mostly material from Ireland but conclusions are expected to also apply to UK-grown material.

To the authors' knowledge, only two studies have addressed and published the properties of Irish timber in tension (Ó Fátharta et al. 2020; Raftery and Harte 2014), and none in the UK. There are no approved grading settings in tension for these countries, and therefore the use of timber in tension relies on the relationships given in the European standards. However, previous experience in bending on British grown conifer species showed that extrapolating models derived from other sources may not fit the characteristics of Irish and UK timber (Gil-Moreno et al. 2016b). In tension, Gil-Moreno et al. (2019a) showed that extrapolating equations derived from the Gradewood project to Irish timber reduced the grading yields.

Likewise, previous studies have found different ratios for the relationship between tension and bending strength. During the drafting of Eurocode 5, Green and Kretschmann (1989) obtained an average $f_{t, 0, k} / f_{m, \mathrm{k}}$ ratio of 0.59 for different softwood species in the US and Canada, with slight changes above $55 \mathrm{~N} / \mathrm{mm}^{2}$ tensile strength. For radiata pine timber, Tsehaye et al. (1997) compiled data from New Zealand and Australia for visual and machine grades that showed a variation of ratios between 0.3 and 0.55 . Based on the brittle fracture theory, and mostly spruce from Central Europe, Burger and Glos (1997) determined a ratio $f_{t, 0, k} / f_{m, \mathrm{k}}$ of 0.69 that increased for higher strengths. In parallel, using this data together with values from the literature, Burger and Glos concluded that tensile strength in EN338:1995 was overrated in the lower strength classes and the contrary for higher strength classes. On Danish-grown Sitka spruce, for a range of $f_{m, k}$ values between 21.7 and $33.6 \mathrm{~N} / \mathrm{mm}^{2}$, and $f_{t, 0, k}$ between 17.1 and $24.4 \mathrm{~N} / \mathrm{mm}^{2}$, Bräuner et al. (2000) found ratios $f_{t, 0, k} / f_{m, \mathrm{k}}$ of $0.66,0.77$ and 0.81 for visual grades $\mathrm{T} 1$, $\mathrm{T} 2$ and $\mathrm{T} 2+$ (from lower to higher quality). More recently, using structural mechanical tests on Norway spruce from Central Europe, Steiger and Arnold (2009) determined that the $f_{t, 0, k} / f_{m, \mathrm{k}}$ ratio depends on timber quality, and based on a linear regression where $27<f_{m, k}<47 \mathrm{~N} / \mathrm{mm}^{2}$ concluded a ratio smaller than 0.6 for $f_{m, k}$ below $22 \mathrm{~N} / \mathrm{mm}^{2}$.

Taking into account the variation in the relationships between wood properties with the sampling sources (Denzler 2012; Stapel and Denzler 2010), and the ratios between tension and bending properties depending on the timber quality, the current study hypothesises that the equation in EN384:2016 underestimates excessively the performance in tension of the lower bending grades in EN338. In fact, N832 states that the old conversion Eq. (1) is generally agreed to be correct for lower grades. The aim of this study is to investigate the relationships between bending and tension characteristic strength of lower-grade timber. The study uses British spruce and Scots pine grown in Ireland and the UK tested in bending and tension. The analysis uses IPs thresholds to create bending and tension subsets of equivalent quality on which to obtain pairs of characteristic values to determine the relationship. Secondly, alternative equations to those given in EN384 are examined combining the current data with those from Scandinavia and Central Europe. This knowledge is particularly important in timber engineering for the optimisation and characterisation of timber used for trusses, I-joist and glulam manufacturing.

\section{Materials and methods}

\subsection{Materials}

Three conifer species were tested in bending and/or tension, namely, Sitka spruce, Norway spruce and Scots pine. The Sitka spruce was grown in Ireland. The bending material (858 pieces) was obtained from a 23 -year-old stand as described in Simic et al. (2019). The Sitka spruce specimens for tension testing (153 pieces) were provided by a sawmill in Ireland as part of the normal production. Due to the large proportion of corewood observed in the material, and aiming to increase the range of values, the tension set was supplemented with 44 additional pieces from a different source (Krajnc et al. 2019a). These additional pieces had a mean length of $1.8 \mathrm{~m}$, shorter than the requirements of the standard EN384 (CEN 2018), but are valid for the purposes of this study.

The Norway spruce came from two plantations 44 years old and one 76 years old in Great Britain (Gil-Moreno et al. 2016a). It was tested in bending (143 pieces) and combined with the bending Sitka spruce dataset so that a wider range of values could be examined.

The Scots pine came from a mixed forest plantation in Ireland of Norway spruce and beech (Fagus sylvatica L.) with Scots pine being a minor component. At the time of felling, it was 77 years of age. A first subset selected 50 pairs of pieces based on similar $E_{d y n}$ and density, as described in Ó Fátharta et al. (2020). The remaining pieces were randomly assigned to give a total of 81 pieces tested in tension and 158 in bending.

The pieces had a nominal cross-section of $100 \times 45 \mathrm{~mm}^{2}$, except for 384 pieces of Sitka spruce tested in bending which had a nominal cross-section of $75 \times 35 \mathrm{~mm}^{2}$. The pieces that either slipped in the tension clamps without reaching a failure point or broke as a result of the clamping pressure were removed from the analysis. Another test was stopped due to safety concerns after reaching a load of $225 \mathrm{kN}$ on a machine with a maximum capacity of $250 \mathrm{kN}$. The inclusion of these pieces in the analysis would have reduced the variation 
of the strength and therefore overestimate the parametric calculations of the percentiles, and it would also affect the relationship of the strength properties with the $E_{d y n}$ and knot index used as IPs.

\subsection{Measurements}

All the material was non-destructively assessed using a Timber Grader MTG 960 (Brookhuis Applied Technologies, Enschede, The Netherlands). This grading machine measures the natural frequency of the vibration produced by the impact of a hammer in the longitudinal direction, and in combination with the density measured from mass and average dimensions, allows calculation of the $E_{d y n}$ using Eq. (4)

$M O E_{d y n}=\mathrm{D} V^{2}=\mathrm{D}(2 F L)^{2} \quad \mathrm{~N} / \mathrm{m}^{2}$

where $\mathrm{D}$ is the density of the full timber piece $\left(\mathrm{kg} / \mathrm{m}^{3}\right), V$ is the acoustic velocity $(\mathrm{m} / \mathrm{s}), F$ the longitudinal natural frequency of the first mode resonance $(\mathrm{Hz})$ and $L$ the piece length (m).

The Scots pine pieces were measured using a Goldeneye 702 Multi-Sensor Quality Scanner (Microtec, Brixen, Italy). This grading machine detects wood defects inside the pieces using the attenuation of $\mathrm{X}$-ray radiation. The critical section to be tested for wood properties measurement was determined from the X-ray images captured and/or visual inspection. The test sections of the Sitka spruce pieces were determined exclusively from visual inspection of wood defects. Following, the TKAR index was measured in the test section. The TKAR is the total projected cross-section areas of all knots within $150 \mathrm{~mm}$ length, divided by the cross-section area of the piece. For the Sitka spruce pieces tested in bending the visual grading standard IS 127 (NSAI 2015) was followed. For the remaining pieces, the online software Web Knot Calculator v2.2 (Microtec, Brixen, Italy) was used. Pieces with TKAR above 0.7 were removed from the analysis as they would certainly be rejected by visual override in production grading.

This study is primarily concerned with the determination of strength values, but for a better characterisation of the material studied, the three key determining properties for grading: $E, f$ and $\rho$, both in tension and bending, were determined following EN408 (CEN 2012). The test section was located at the centre of the span. When tested in tension, a transducer was placed on each face of the piece, and the average displacement was used for the calculations of $E_{t}$. When tested in bending, the global modulus of elasticity was measured in the top face in Sitka spruce and the bottom face in the rest of the species and adjusted as given in EN384. A sample free of defects obtained from near the failure point was used for the calculation of the clear density $(\rho)$, and moisture content (mc) according to EN13183-1 (CEN 2002).
The $E$ and $\rho$ values were corrected to a reference $12 \% \mathrm{mc}$, and $f$ was adjusted to a $150 \mathrm{~mm}$ reference depth following the EN384 (CEN 2018).

\subsection{Data analysis}

The statistical analysis was carried out with the open-source statistical environment R (R Core Team 2019).

First, a descriptive summary of the wood properties was investigated, and the linear relationships between them examined. The relationship between the strength properties and $E_{d y n}$, and TKAR were examined further by conducting an analysis of variance (ANOVA) with Eq. (5) that also tested the influence of the two species groups (British spruce and Scots pine) in the relationships, both in tension and bending.

$f=\alpha_{0}+\alpha_{1} I P+\alpha_{2}$ Species $+\alpha_{3} I P:$ Species $+\varepsilon$

where $\alpha_{0}$ is the intercept term, $\alpha_{1}$ is the slope, $\alpha_{2}$ represents the additive effect of the species studied on the intercept term, $\alpha_{3}$ is the interaction term between the IP used ( $E_{d y n}$ or $T K A R$ ) and species and $\varepsilon$ is the residual error not explained by the model. The ANOVA conducted was type III to account for the unbalanced number of pieces in each group.

In addition, $E_{d y n}$ and TKAR were used in a multiple linear regression to model the strength properties in bending and tension. The models were applied by species to every piece, which allowed two additional IPs, $I P_{m}$ and $I P_{t}$ to be obtained. Thus, each piece had four IPs: $E_{d y n}, T K A R, I P_{m}$ and $I P_{t}$. The goodness-of-fit $\left(\mathrm{R}^{2}\right)$ of the linear models was measured as the coefficient of determination, and for non-linear models as the correlation between observed and predicted values. The model performance was also assessed using the mean absolute percentage error (MAPE) and for comparison of models the Akaike's information criterion (AIC). Next, the datasets in bending and tension were subset using different IP thresholds to create bending and tension groups of equivalent quality on which to calculate the characteristic values of $f_{m, k}$ and $f_{t, 0, k}$. Nine groups per IP were created using thresholds based on boxplots to cover the range of strength values in the datasets. The characteristic strength values were calculated according to the standard EN14358 (CEN 2016b), using the nonparametric calculation without confidence interval when $n \geq 40$ pieces, and the lognormal distribution when $\mathrm{n}<40$ using $75 \%$ confidence level (to take into account the smaller number of pieces). Subsets with less than 20 pieces were removed from further analysis, leaving 35 groups for spruce and 29 for Scots pine. The relationship between the pairs of values from each subset was investigated, and the lower 75\%-prediction line around the regression was established. This approach was used for deriving an empirical conversion from characteristic bending strength 
to characteristic tension strength and vice versa. Finally, the process was repeated combining the data obtained in the current study with the N832 data. The linear regression assumptions were examined and addressed when violated. This approach is a simplified version of real grading and is similar to the approach used in N832.

\section{Results and discussion}

\subsection{Descriptive statistics and model fitting}

A descriptive summary of the quality of the material studied is given in Table 1. Note that the comparison between species only applies to the particular data in the current study, and should not be interpreted as a broad comparison between species as the datasets are not representative for that purpose. The grading of British spruce was limited by stiffness. In bending, the whole population achieved a grade of $\mathrm{C} 14$, and $74 \%$ yield a grade of C16. The Sitka spruce dataset on its own did not achieve $\mathrm{C} 14$. This is lower than the near $100 \%$ yield of C16 normally achieved, as a consequence of the particular resource sampled. In tension, the whole population achieved a T11 strength class, and more than $90 \%$ a $\mathrm{T} 12$.

Scots pine was limited by strength. The whole population of Scots pine achieved C16 in bending (almost 90\% a grade of C22), and T8 in tension (almost 90\% T11). Table 1 shows a large variation in the strength values of Scots pine, which was reflected in lower values of $f_{m, k}$ and $f_{t, 0, k}$ than expected considering that $E$ achieves $\mathrm{C} 22$ and T10 requirements. The Scots pine came from one single batch, and the density values in the tension and bending datasets are comparable, but the difference observed in the $E_{d y n}$ at the time of testing advises against assuming an equivalence of the $\mathrm{C} 16$

Table 1 Summary of the wood properties (in brackets the coefficient of variation in \%)

\begin{tabular}{llllll}
\hline & \multicolumn{2}{l}{ British spruce } & & \multicolumn{2}{l}{ Scots pine } \\
\cline { 2 - 3 } \cline { 5 - 6 } \cline { 5 - 6 } & Bending & Tension & & Bending & Tension \\
\hline Number of pieces & 1001 & 141 & & 158 & 61 \\
$E_{m, 0, \text { mean }}$ or $E_{t, 0, \text { mean }}$, & $6.74(31)$ & $8.56(20)$ & $9.50(29)$ & $8.23(29)$ \\
$\mathrm{kN} / \mathrm{mm}^{2}$ & & & & & \\
$f_{m, \text { mean }}$ or $f_{t, 0, \text { mean }}, \mathrm{N} / \mathrm{mm}^{2}$ & $30.8(28)$ & $23.5(24)$ & $38.2(39)$ & $19.4(42)$ \\
$f_{m, k}$ or $f_{t, 0, k}, \mathrm{~N} / \mathrm{mm}^{2}$ & 18.0 & 15.2 & & 17.2 & 8.52 \\
$\rho, \mathrm{kg} / \mathrm{m}^{3}$ & $381(10)$ & $387(9)$ & $521(10)$ & $507(8)$ \\
$\rho_{k}, \mathrm{~kg} / \mathrm{m}^{3}$ & 326 & 335 & & 443 & 437 \\
$E_{\text {dyn }}, \mathrm{kN} / \mathrm{mm}^{2}$ & $8.89(19)$ & $10.0(17)$ & $11.2(21)$ & $9.96(24)$ \\
Approximate strength & $\mathrm{C} 14$ & $\mathrm{~T} 11$ & $\mathrm{C} 16$ & $\mathrm{~T} 8$ \\
$\quad$ class & & & & \\
\hline
\end{tabular}

British spruce is a species combination of Sitka spruce and Norway spruce and T8 strength classes. The tension and bending datasets of spruce came from different batches. They were comparable in terms of density, but an equivalence between properties is not expected. Spruce graded lower than Scots pine in bending (C14), but higher in tension (T11). Thus, the different behaviour of the two species, and its likely effect on the relationships between wood properties, is a first indication that the relationship between bending strength and tension strength may vary by species.

In bending, the results of spruce are slightly lower than the average reported in the literature for Irish-grown timber likely due to the large proportion of young material compared to normal saw logs. In tension (for which the spruce specimens were more typical of the normal resource), the mechanical properties are slightly higher than those reported in Ireland by Raftery (2010), who on $25 \times 96 \mathrm{~mm}^{2}$ pieces obtained mean values of $E_{t}=7.89 \mathrm{kN} / \mathrm{mm}^{2}, \rho=403 \mathrm{~kg} / \mathrm{m}^{3}$ and $f_{t}=20.9 \mathrm{kN} / \mathrm{mm}^{2}$ adjusted to the reference conditions. Higher values were found for Danish-grown Sitka spruce (Bräuner et al. 2000) and Scandinavian spruce (Briggert et al. 2020), but this difference was expected. The results for pine are comparable to those found in Scotland for pure plantations of approximately 80 years of age reported by Moore et al. (2008) and for density and $E$ measured on clears by Auty et al. (2016). Again, higher mechanical properties are achieved for Scandinavian and Central European Scots pine, with comparable density (Hautamäki et al. 2014; Ranta-Maunus 2007; Stapel and Denzler 2010), but this is an expected result.

The strengths of the linear associations between the properties studied are shown in Table 2. The relationships were, in general, stronger in pine than in spruce. The coefficients of determination between the mechanical properties of British spruce in tension are slightly lower than those found by Bräuner et al. (2000) on Danish-grown Sitka spruce $\left(\mathrm{R}^{2}=0.41\right)$ and by Briggert et al. (2020) on Scandinavian spruce $\left(R^{2}=0.48\right)$. For the mechanical properties in bending, Bräuner et al. (2000) reported $R^{2}=0.30$ and $R^{2}=0.56$ for two different populations. In the current study the linear relationship between density and the mechanical properties of spruce in tension is not significant, but in Briggert et al. (2020) density explained $23 \%$ and $53 \%$ of the variation of $f_{t}$ and $E_{t}$, respectively. The difference may be associated with the large amount of corewood observed in the current dataset. Density in spruce decreases from near the pith during the first 10-12 years and increases thereafter (Gardiner et al. 2011; Saranpää 2003), whereas the mechanical properties increase from the pith outwards. Thus, Raftery and Harte (2014) also found a very low correlation between density and the mechanical properties of Irish spruce in tension, but a moderate correlation $\left(\mathrm{R}^{2}=0.59\right)$ between the mechanical properties. McLean et al. (2016) did not find a significant relationship between density and $E_{m}$ for clears sampled 
Table 2 Coefficients of determination $\mathrm{R}^{2}$ and significance ( $p$-value) of linear models where the null hypothesis is that the explanatory variable has no effect on the response variable

\begin{tabular}{|c|c|c|c|c|c|c|}
\hline \multirow[t]{2}{*}{$\overline{\mathrm{R}^{2}}$} & \multicolumn{3}{|l|}{ Bending } & \multicolumn{3}{|l|}{ Tension } \\
\hline & Overall & British spruce & Scots pine & Overall & British spruce & Scots pine \\
\hline$\rho-E$ & $0.37 * * *$ & $0.28 * * *$ & $0.24 * * *$ & $0.01(\mathrm{~ns})$ & 0.01 (ns) & $0.46 * * *$ \\
\hline$\rho-f$ & $0.23 * * *$ & $0.22 * * *$ & $0.23 * * *$ & $0.01(\mathrm{~ns})$ & $0.01(\mathrm{~ns})$ & $0.38 * * *$ \\
\hline$E-f$ & $0.54 * * *$ & $0.49 * * *$ & $0.55^{* * *}$ & $0.46 * * *$ & $0.33 * * *$ & $0.67 * * *$ \\
\hline$E_{d y n}-E$ & $0.75 * * *$ & $0.69 * * *$ & $0.79 * * *$ & $0.72 * * *$ & $0.75^{* * *}$ & $0.70 * * *$ \\
\hline$E_{d y n}-f$ & $0.34 * * *$ & $0.26^{* * *}$ & $0.40 * * *$ & $0.33 * * *$ & $0.31 * * *$ & $0.45^{* * *}$ \\
\hline$T K A R-f$ & $0.16^{* * *}$ & $0.07 * * *$ & $0.64 * * *$ & $0.10 * * *$ & $0.05^{*}$ & $0.55^{* * *}$ \\
\hline
\end{tabular}

ns non-significant

$p$-value: '***' $<0.001,{ }^{\prime *}$ ' $<0.05$ from the corewood, but neither did Alteyrac et al. (2007) for 80 -year-old black spruce.

Stronger relationships were found in the current study between $E_{d y n}$ and $E$ in bending and tension, similar to those by Steiger and Arnold (2009) for Swiss-grown Norway spruce $\left(R^{2}=0.60\right.$ and $R^{2}=0.80$, respectively) and slightly lower than between $E_{d y n}$ and $f\left(\mathrm{R}^{2}=0.39\right.$ in bending and $\mathrm{R}^{2}=0.34$ in tension). In Scandinavia, Briggert et al. (2020) observed a similar relationship between $E_{d y n}$ and $E_{t}$ $\left(\mathrm{R}^{2}=0.81\right)$, but stronger than in the current study between $E_{d y n}$ and $f_{t}\left(\mathrm{R}^{2}=0.46\right)$. This variability is not unusual within a species, and is experienced in real production. For beech, Ehrhart et al. $(2016,2018)$ reported poor relationships between $E_{d y n}$ and $f_{t, 0}\left(\mathrm{R}^{2}=0.22\right.$ and 0.16$)$ whereas Westermayr et al. (2018) reported $\mathrm{R}^{2}=0.51$.

Using TKAR as predictor variable explained a higher percentage of the variation in $f$ than $E_{d y n}$ in Scots pine, but explained very little of the variance of spruce in bending $\left(\mathrm{R}^{2}=0.05\right.$ in Sitka and 0.24 in Norway spruce). Evidence from other studies suggests that cross-section sizes have a large influence in visual grading (Stapel and Van De Kuilen 2014), and this may partially explain the poor relationship between TKAR and $f_{m}$ (that included two cross-sections), but it would not explain the poor relationship observed in tension. On 83 pieces of Irish spruce, Raftery and Harte (2014) found stronger relationships, and TKAR explained 39\% of the variation of $f_{t, 0}$.

The relationships were examined further by conducting an ANOVA type III with Eq. (5) between $E_{d y n}$ and the strength properties to determine whether the same prediction model could be used for both species. In bending, the slope of the relationship changed with species $\left(F_{11154}=16.2, p<0.001\right)$. In tension, the slope was statistically the same for the two species $\left(F_{1205}=2.3, p=0.13\right)$, but there was an additive effect of species $\left(F_{1206}=26.8\right.$, $p<0.001)$ that meant Sitka spruce had a higher intercept term than Scots pine. Figure 1 shows the relationship of $E_{d y n}$ with strength. The same test determined that the influence of knots on the strength also differed by species, affecting both the intercept and slope in bending

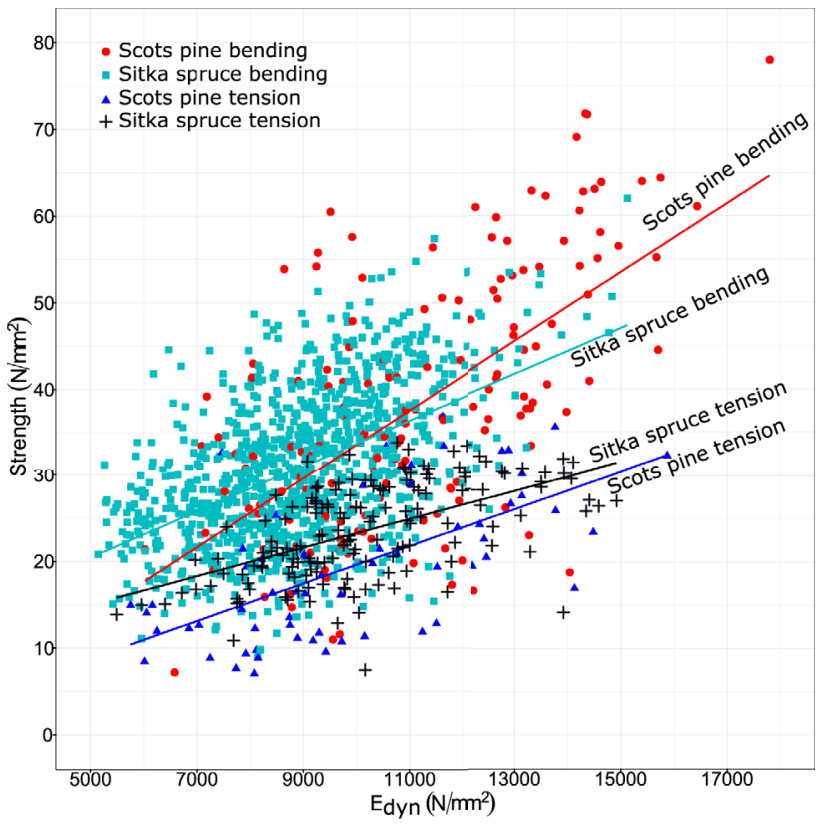

Fig. 1 Relationship between $E_{d y n}$ and strength in tension and bending

$\left(F_{11153}=121, p<0.001\right.$ and $\left.F_{11152}=91.3, p<0.001\right)$ and in tension $\left(F_{1198}=48.9, p<0.001\right.$ and $F_{1197}=28.3$, $p<0.001$ ).

In a multiple linear regression, both $E_{d y n}$ and TKAR were significant $(p<0.001)$ as predictor variables of strength, with stronger relationships in Scots pine than in spruce as shown in Table 3 (with a 90\% confidence interval calculated by bootstrapping for each dataset). The regressions did not improve appreciably by including density. In line with the ANOVA with Eq. (5), the large error found for the overall tension dataset (MAPE $=45 \%)$ compared to the species models (around 20\%) advises against using the same equation for the prediction of strength in the two species.

The parameters of the regressions in Table 3 were quite different between the species for the same strength property, particularly for the intercept and TKAR index. These large differences were not observed in the Gradewood datasets 
Table 3 Fit statistics for the strength equations for spruce $(B S)$ and pine $(S P)$ in bending $(m)$ and tension $(t)$ for the model-fitting datasets, and validation dataset (underlined)

\begin{tabular}{|c|c|c|c|c|c|c|c|c|}
\hline & \multirow[t]{2}{*}{ Intercept } & \multicolumn{2}{|l|}{ Slope } & \multirow[t]{2}{*}{$\mathrm{R}^{2}$} & \multirow[t]{2}{*}{ RMSE $\left(\mathrm{N} / \mathrm{mm}^{2}\right)$} & \multirow[t]{2}{*}{ MAPE \% } & \multicolumn{2}{|c|}{$\begin{array}{l}\text { Predicted } \\
\text { mean value } \\
\mathrm{N} / \mathrm{mm}^{2}\end{array}$} \\
\hline & & TKAR & $E_{\text {dyn }}$ & & & & $m$ & $t$ \\
\hline$f_{t}$ & 5.810 & -6.138 & $1.893 \bullet 10^{-3}$ & 0.36 & 5.40 & $45 \%$ & 30.2 & 22.2 \\
\hline $5 \%$ & 1.291 & -10.93 & $1.523 \bullet 10^{-3}$ & 0.28 & & & & \\
\hline $95 \%$ & 10.78 & -1.726 & $2.241 \bullet 10^{-3}$ & 0.44 & & & & \\
\hline$f_{m}$ & 13.83 & -30.96 & $2.809 \bullet 10^{-3}$ & 0.45 & 7.45 & $21 \%$ & 31.8 & 22.7 \\
\hline $5 \%$ & 11.97 & -35.98 & $2.600 \bullet 10^{-3}$ & 0.41 & & & & \\
\hline $95 \%$ & 16.38 & -27.60 & $3.024 \bullet 10^{-3}$ & 0.50 & & & & \\
\hline$I P_{t, B S}$ & 8.934 & -5.452 & $1.692 \bullet 10^{-3}$ & 0.30 & 8.33 & $18 \%$ & $\underline{29.6}$ & 23.5 \\
\hline $5 \%$ & 4.083 & -10.85 & $1.190 \bullet 10^{-3}$ & 0.20 & & & & \\
\hline $95 \%$ & 15.10 & -0.476 & $2.050 \bullet 10^{-3}$ & 0.43 & & & & \\
\hline$I P_{m, B S}$ & 13.06 & -22.22 & $2.626 \bullet 10^{-3}$ & 0.32 & 7.16 & $21 \%$ & 30.8 & $\underline{22.6}$ \\
\hline $5 \%$ & 10.89 & -25.64 & $2.290 \bullet 10^{-3}$ & 0.28 & & & & \\
\hline $95 \%$ & 16.00 & -16.03 & $2.823 \bullet 10^{-3}$ & 0.36 & & & & \\
\hline$I P_{t, S P}$ & 16.12 & -28.26 & $1.290 \bullet 10^{-3}$ & 0.65 & 4.88 & $23 \%$ & $\underline{31.7}$ & 19.4 \\
\hline $5 \%$ & 6.636 & -36.06 & $0.804 \bullet 10^{-3}$ & 0.53 & & & & \\
\hline $95 \%$ & 23.21 & -18.18 & $1.945 \bullet 10^{-3}$ & 0.78 & & & & \\
\hline$I P_{m, S P}$ & 30.43 & -55.59 & $2.022 \bullet 10^{-3}$ & 0.71 & 7.93 & $19 \%$ & 38.4 & $\underline{23.1}$ \\
\hline $5 \%$ & 22.85 & -62.37 & $1.533 \bullet 10^{-3}$ & 0.65 & & & & \\
\hline $95 \%$ & 37.40 & -47.34 & $2.598 \bullet 10^{-3}$ & 0.78 & & & & \\
\hline
\end{tabular}

The regression coefficients for the 5-95\% confidence interval are calculated by bootstrapping each dataset
(Ranta-Maunus et al. 2011), that showed relationships with the predictor variables more comparable between the species. If the tension equations in the Gradewood project were extrapolated to the current dataset, one piece of Scots pine and another of Sitka spruce would give negative tensile strength. Although these equations may not have been used for the document N832 (only data from countries where both bending and tension tests were carried out were used), they show the differences that can be found for different populations, and the impact when applied to different datasets. Table 3 also shows the predicted mean values of the models applied to the individual pieces, which allows a comparison of the performance of the datasets studied under bending and tension. Thus, for the predicted values the study found ratios $f_{t} / f_{m}$ of 0.79 and 0.73 for spruce, 0.61 and 0.60 for pine. Likewise, Bräuner et al. (2000) found ratios $f_{t} / f_{m}$ of 0.74 and 0.78 for visual grades $\mathrm{T} 1$ and $\mathrm{T} 2+$ that are comparable to $\mathrm{C} 18$ and $\mathrm{C} 24$. The relationships between bending and tension strength predicted on individual pieces from models $I P_{t, B S}$, $I P_{m, B S}, I P_{t, S P}$ and $I P_{m, S P}$ are shown in Fig. 2 together with the strength measured, in bending or tension, for each board.

\subsection{Conversion from characteristic bending strength to characteristic tension strength}

Based on the previous analysis, the relationship between the characteristic strength values in tension and bending was determined by species in the first instance. Using nine thresholds for each IP $\left(E_{d y n}, T K A R, I P_{m}\right.$ and $\left.I P_{t}\right)$, the bending and tension datasets were divided into subsets aimed at creating groups of equivalent quality on which to calculate

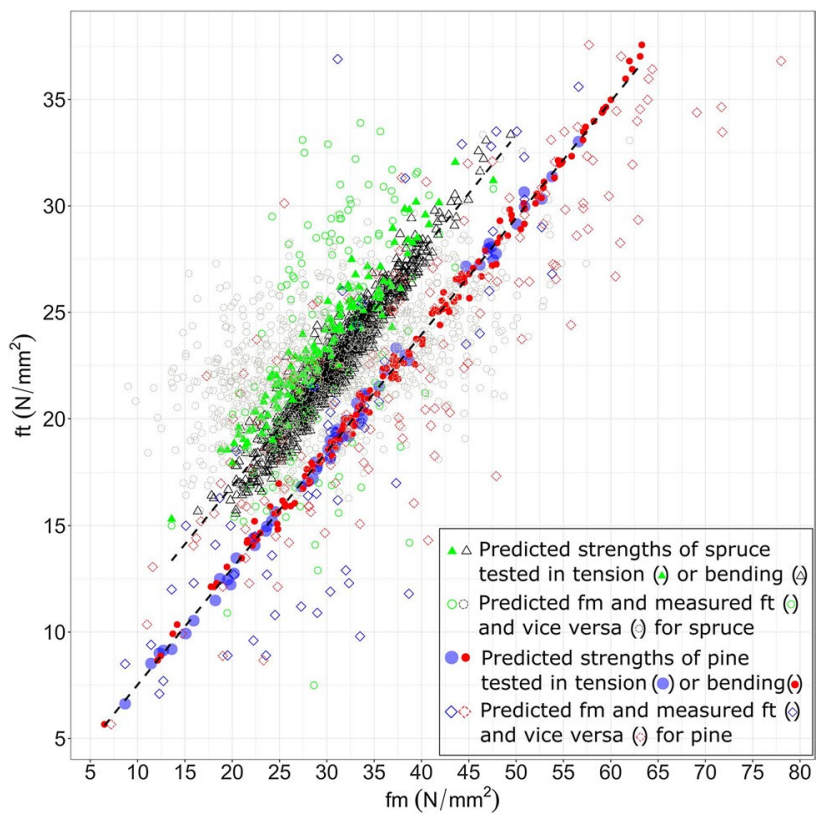

Fig. 2 Measured values of the strength properties and relationships on boards between bending and tension strength predicted from models using $E_{d y n}$ and TKAR as independent variables 


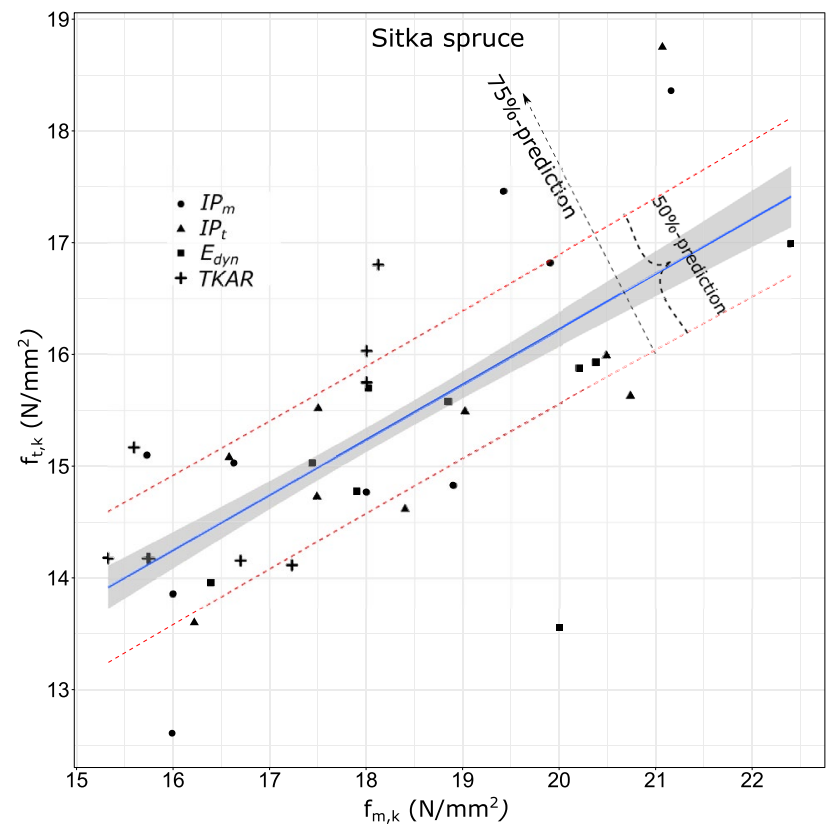

Fig. 3 Regression line (solid) with 50\%-confidence intervals for the prediction of characteristic tension strength for British spruce. The lower dashed bound shows the 50\%-prediction for the single observations

the characteristic values of strength in bending and tension. Subsets with less than 20 pieces were discarded. Following the standard EN14358 (CEN 2016b), the nonparametric method for strength was used when $n \geq 40$ pieces, and the lognormal distribution was used when $n<40$ using a $75 \%$ confidence level. The analysis is inevitably sensitive to the method of calculation of percentiles. For comparison with the analysis in N832, the use of the empirical lognormal distribution was investigated irrespective of the number of pieces, resulting in higher characteristic strength values in $76 \%$ of the subsets created.

A regression analysis between the characteristic values of strength in bending and tension determined a moderate relationship for spruce (Fig. 3, $\mathrm{R}^{2}=0.50$ and $\mathrm{RMSE}=0.95 \mathrm{~N} /$ $\mathrm{mm}^{2}$ ) that met the linear regression assumptions. For Scots pine, a linear regression was very strong $\left(\mathrm{R}^{2}=0.83\right.$, $\mathrm{RMSE}=1.06 \mathrm{~N} / \mathrm{mm}^{2}$ ) and had the same slope as spruce

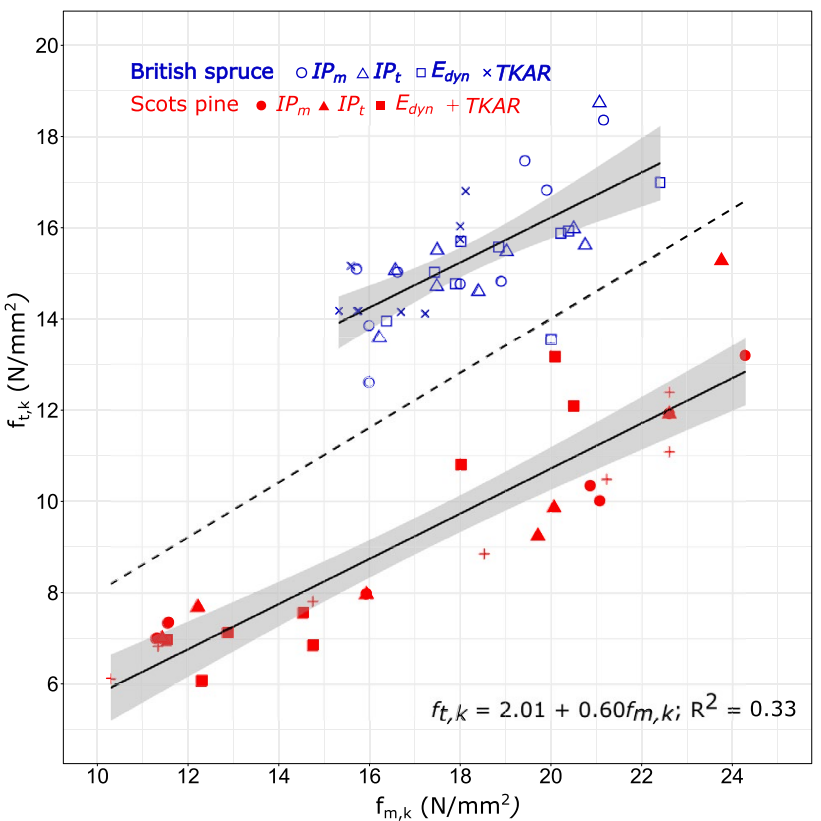

Fig. 4 Regression lines with 95\% confidence interval for different $I P$ s and species (solid line), and for the two species together (dash line)

$\left(0.49 \mathrm{fm}_{, k}\right)$, but did not meet the linear regression assumptions. A logarithmical transformation of the response variable improved the relationship while keeping the linear model $\left(\mathrm{R}^{2}=0.87, \mathrm{RMSE}=0.04\right)$. After fitting the regression models, the value of a new observation of the dependent variable $f_{t, k}$ was calculated for a $50 \%$-prediction interval. As a result, there is a $75 \%$ probability that the predicted value will be above the lower bound. This allowed a conservative conversion to be obtained. The average strength ratio $f_{t, k} / f_{m, k}$ of the subsets in spruce was 0.85 , with a range between 0.68 and 0.97 . The average strength ratio $f_{t, k} / f_{m, k}$ in pine was 0.55 , with a range between 0.47 and 0.66 . Table 4 gives the conversion equations.

Establishing a linear regression for the two species together gave a weak coefficient of determination $\left(\mathrm{R}^{2}=0.33\right)$. Figure 4 shows the large difference in the intercept term of the two species separately. The relationship however gives the same slope as the old EN384 conversion. Figure 4 also shows the lower variation of bending strength values of spruce compared to pine.
Table 4 Conversion equations by species and in combination with N832 data

\begin{tabular}{llll}
\hline Dataset & Regression models & & Lower 75\%-prediction \\
\hline British spruce & $f_{t, 0, k}=6.35+0.49 f_{m, k}$ & Equation (6) & $f_{t, 0, k}=5.68+0.49 f_{m, k}$ \\
Scots pine & $\log _{10}\left(f_{t, 0, k}\right)=0.56+0.023 f_{m, k}$ & Equation (7) & $\log _{10}\left(f_{t, 0, k}\right)=0.532+0.023 f_{m, k}$ \\
Current study and N832 & $f_{t, 0, k}=0.54+0.651 f_{m, k}$ & Equation (8) & $f_{t, 0, k}=-1.08+0.653 f_{m, k}$ \\
British spruce & $f_{m, 0, k}=2.74+1.005 f_{t, k}$ & Equation (9) & $f_{m, 0, k}=1.79+1.005 f_{t, k}$ \\
Scots pine & $f_{m, k}=24.57\left(1-e^{\left.\frac{\ln \left(\frac{1}{7.5}\right)}{5.71} f_{t, k}\right)^{7.5}}\right.$ & Equation (10) & $f_{m, k}=23.27\left(1-e^{\left.\frac{\ln \left(\frac{1}{8.98}\right)}{5.93} f_{t, k}\right)^{8.98}}\right.$ \\
Current study and N832 & $f_{m, k}=4.238+1.203 f_{t, k}$ & Equation (11) & $f_{m, k}=2.03+1.203 f_{t, k}$ \\
\hline
\end{tabular}




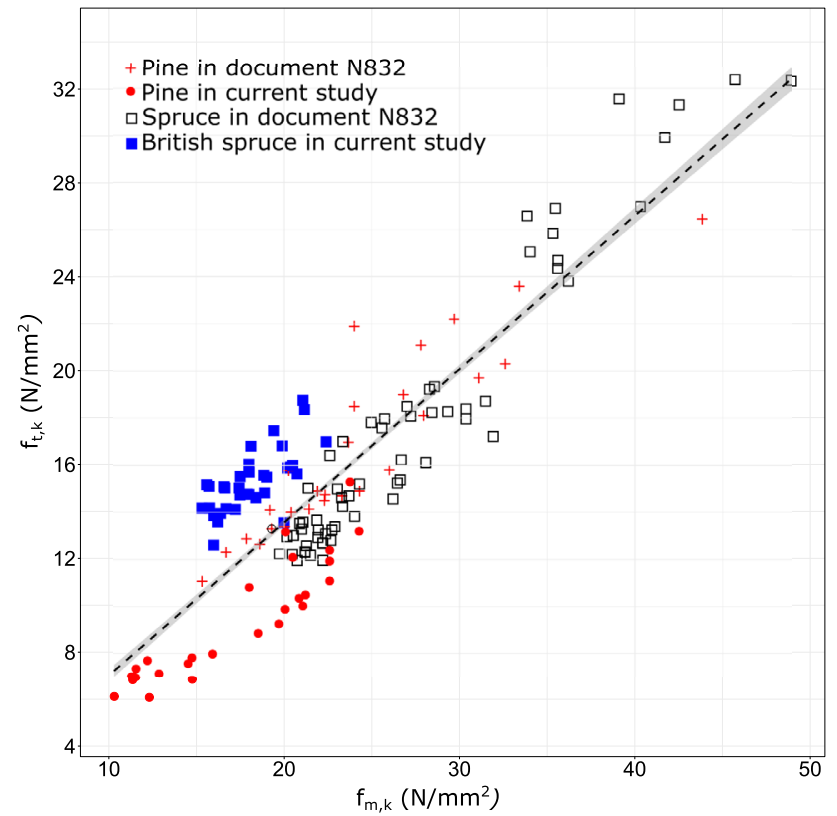

Fig. 5 Regression line (dash line) and 95\% confidence interval combining the current study and data from document N832

A new model was further developed by combining the data from the document N832 with the current dataset. Figure 5 shows the relationship between the characteristic strength values in bending and tension for the combined dataset. The range of characteristic strength values was higher in N832 than in the current study. From the regression model of Eq. (8), a $\mathrm{R}^{2}=0.79$ was found, which is slightly lower than that in $\mathrm{N} 832\left(\mathrm{R}^{2}=0.88\right.$, Eq. (2)). Combining the data from document $\mathrm{N} 832$ with only the spruce dataset, a linear regression gave a coefficient of determination of $\mathrm{R}^{2}=0.77$, whereas combining N832 with only the pine dataset was $\mathrm{R}^{2}=0.90$.
By using Eq. (6) the characteristic tension strength of Irish-grown spruce calculated from bending increased compared to Eq. (2). The difference is particularly large for C16, with a ratio $f_{t, 0, k} / f_{m, k}$ of 0.85 that decreases to 0.65 for $\mathrm{C} 35$. Based on the low correlation between the strength properties and the $T K A R$, an alternative equation was explored without the subsets created using the TKAR, but the results were similar to those given by Eq. (6). On the contrary, the resulting Eq. (7) for Scots pine offered lower characteristic tension strength values than Eq. (2), with a ratio $f_{t, 0, k} / f_{m, k}$ of 0.50 that increased from $\mathrm{C} 22$ up to 0.62 for $\mathrm{C} 35$. When including the $\mathrm{N} 832$ data the differences are lower (9\% for $\mathrm{C} 16$ and $1 \%$ for $\mathrm{C} 24$ ), with a ratio $f_{t, 0, k} / f_{m, k}$ of 0.59 that increased to 0.62 for C35. A comparison can be observed in Table 5 for some of the most common strength classes.

\subsection{Conversion from characteristic tension strength to characteristic bending strength}

The approach used above was then used to estimate the characteristic tension strength from the bending strength. A regression analysis found a moderate relationship for spruce $\left(\mathrm{R}^{2}=0.50 ; \mathrm{RMSE}=1.36 \mathrm{~N} / \mathrm{mm}^{2}\right)$, and the lower $75 \%$-prediction equation, Eq. (9), gave lower characteristic bending strength values than the standard conversion Eq. (3). For Scots pine, a regression model $\left(\mathrm{R}^{2}=0.83 ; \mathrm{RMSE}=1.9 \mathrm{~N} /\right.$ $\mathrm{mm}^{2}$ ) found a slope $1.68 f_{t, 0, k}$, but the relationship was described better with a non-linear model. A logarithmical transformation improved the relationship, but the linear assumptions were not met. Various exponential functions were screened and analysed. An exponential model has the advantage of overcoming the uncertainties of a linear model when extrapolating beyond the data collected. Equation (10) gave the lowest Akaike's information criterion (AIC) and

Table 5 Characteristic strength values $\left(\mathrm{N} / \mathrm{mm}^{2}\right.$ ) obtained using equations in the European standards (Eq. 1, Eq. 2 and Eq. 3) and those derived in the current study (Eq. 6, Eq. 7, Eq. 8, Eq. 9, Eq. 10 and Eq. 11)

\begin{tabular}{|c|c|c|c|c|c|c|c|}
\hline & \multirow[b]{2}{*}{ Equation } & \multirow[b]{2}{*}{ Year/Project } & \multicolumn{5}{|c|}{ Bending strength classes to tension strength values } \\
\hline & & & $\mathrm{C} 16$ & $\mathrm{C} 18$ & $\mathrm{C} 20$ & $\mathrm{C} 22$ & $\mathrm{C} 24$ \\
\hline \multirow[t]{7}{*}{$f_{m, k}$ to $f_{t, 0, k}$} & Equation 1 & 2009/EN338 & 9.60 & 10.8 & 12 & 13.2 & 14.4 \\
\hline & Equation 2 & 2016/N832 & 8.61 & 10.07 & 11.53 & 12.99 & 14.45 \\
\hline & Equation 6 & 2021/British spruce & 13.52 & 14.50 & 15.48 & 16.46 & 17.44 \\
\hline & Equation 7 & 2021/Scots pine & 7.96 & 8.85 & 9.83 & 10.92 & 12.13 \\
\hline & Equation 8 & 2021/Current study and N832 & 9.37 & 10.67 & 11.98 & 13.28 & 14.59 \\
\hline & Equation & Year/Project & \multicolumn{5}{|c|}{ Tension strength classes to bending strength values } \\
\hline & & & $\mathrm{T} 8$ & T9 & T10 & T11 & T12 \\
\hline \multirow[t]{4}{*}{$f_{t, 0, k}$ to $f_{m, k}$} & Equation 3 & 2016/N832 & 13.4 & 14.6 & 15.8 & 17.0 & 18.2 \\
\hline & Equation 9 & 2021/British spruce & 9.8 & 10.8 & 11.8 & 12.8 & 13.9 \\
\hline & Equation 10 & 2021/Scots pine & 14.4 & 16.8 & 18.6 & 19.9 & 20.9 \\
\hline & Equation 11 & 2021/Current study and N832 & 11.7 & 12.9 & 14.1 & 15.3 & 16.5 \\
\hline
\end{tabular}




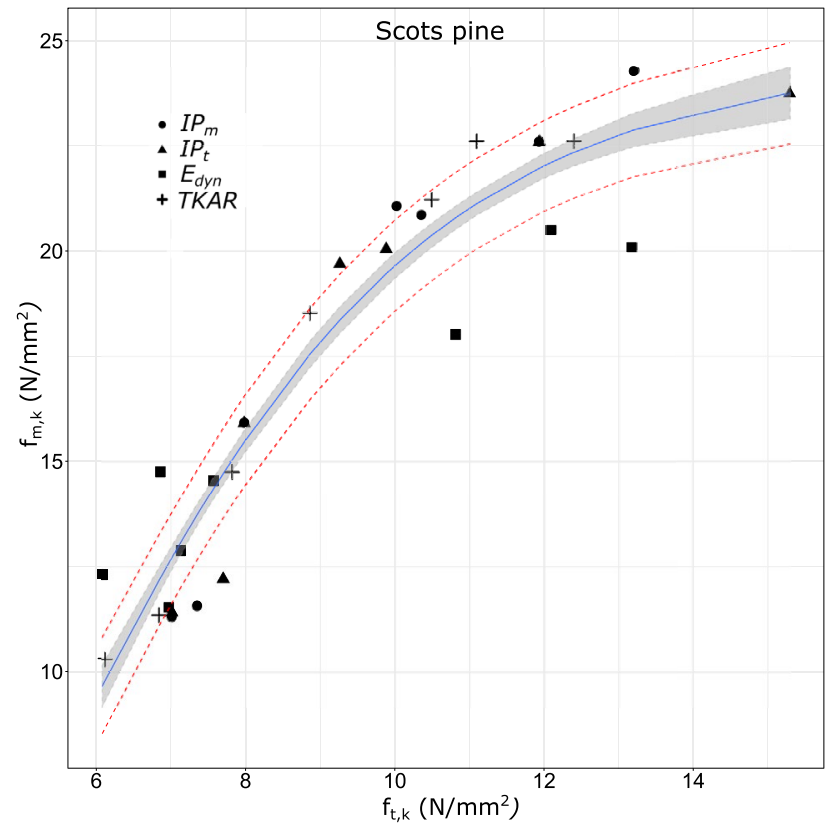

Fig. 6 Relationship with 50\%-confidence intervals for the prediction of characteristic bending strength for Scots pine. The lower dashed bound shows the 50\%-prediction for the single observations

the best fit (Fig. 6), explaining $90 \%$ of the variation in $f_{m, k}$, and gave higher values than the standard conversion Eq. (3).

A new model was further developed by combining the data from the document $\mathrm{N} 832$ with the current dataset. The regression model between the characteristic strength values in tension and bending, Eq. (11), gave a relationship of $\mathrm{R}^{2}=0.78$, slightly lower than that reported in $\mathrm{N} 832$ $\left(\mathrm{R}^{2}=0.88\right.$; Eq. (3)). The lower $75 \%$-prediction of the regression line produced values around $12 \%$ lower than the standard conversion, Eq. (3). The model needs to be carefully considered for values above $f_{t, 0, k}>30 \mathrm{~N} / \mathrm{mm}^{2}$ due to the smaller number of pairs analysed and the larger confidence interval. A comparison for some of the most common strength classes is given in Table 5 .

\section{Conclusion}

This study analysed the relationship between bending and tension strength properties of two conifer species in Ireland and the UK, with a particular focus on British spruce as the main commercial timber species in both countries. The study demonstrates the importance of timber quality and origin in the determination of the relationships between the bending and tension properties. Differences in the mechanical behaviour between species can also play an important role and may not conform with the assumed linear relationship given in the European standards. The study focused on the strength properties in bending and tension as key parameters in the conversion between bending and tension strength classes. The study examined timber with characteristic values of $\mathrm{C} 14, \mathrm{C} 16, \mathrm{~T} 8$ and $\mathrm{T} 11$. For spruce, a linear regression modelled the relationship between the bending and tension characteristic strength values, whereas for Scots pine a non-linear relationship fits better.

The study finds that the conversion equation given in the European grading standards, derived using higher strength classes and extrapolated to lower grades, significantly underestimates the characteristic tension strength values of Irish-grown spruce that in Ireland typically achieves C16 bending strength classes. The contrary occurs on the reverse conversion. Smaller differences were found on Scots pine, but in this case the standard overestimates the conversion from characteristic bending strength to characteristic tension strength.

Additionally, the study combined data from continental Europe with the current dataset to establish a new conversion equation that improves the predicted tension strength of Irish spruce obtained from bending strength classes while ensuring safe values for design and economic viability. Further analysis including more pieces tested in tension and from older plantations of Sitka spruce is advised before a possible revision of the European standards could be considered.

Acknowledgements This work was developed within the WoodProps programme funded by the Forest Sector Development Division of the Department of Agriculture, Food and the Marine, Ireland. The authors are grateful to Coillte and ECC Timber Products for the material supplied, Murray Timber Group and MICROTEC for the use of the Goldeneye 702, and Karlo Simic, Colm Walsh, Cian Ó Fátharta (NUIG) and Stefan Lehneke (ENU) for their contributions to the production of the datasets examined.

Funding Open Access funding provided by the IReL Consortium. This research was funded by the Forest Sector Development Division of the Department of Agriculture, Food and the Marine, Ireland.

Availability of data and material The datasets generated during and/or analysed during the current study are available from the corresponding author on reasonable request.

\section{Declarations}

Conflict of interest On behalf of all authors, the corresponding author states that there is no conflict of interest.

Open Access This article is licensed under a Creative Commons Attribution 4.0 International License, which permits use, sharing, adaptation, distribution and reproduction in any medium or format, as long as you give appropriate credit to the original author(s) and the source, provide a link to the Creative Commons licence, and indicate if changes were made. The images or other third party material in this article are included in the article's Creative Commons licence, unless indicated otherwise in a credit line to the material. If material is not included in the article's Creative Commons licence and your intended use is not 
permitted by statutory regulation or exceeds the permitted use, you will need to obtain permission directly from the copyright holder. To view a copy of this licence, visit http://creativecommons.org/licenses/by/4.0/.

\section{References}

Alteyrac J, Zhang S, Cloutier A, Ruel J-C (2007) Influence of stand density on ring width and wood density at different sampling heights in black spruce (Picea mariana (Mill.) BSP). Wood Fiber Sci 37:83-94

Auty D, Achim A, Macdonald E, Cameron AD, Gardiner BA (2016) Models for predicting clearwood mechanical properties of Scots pine. For Sci 62:403-413

Bräuner L, Hoffmeyer P, Poulsson L (2000) Mechanical properties of Picea sitchensis. Scand J for Res 15:127-134. https://doi.org/10. 1080/02827580050160565

Briggert A, Olsson A, Oscarsson J (2020) Prediction of tensile strength of sawn timber: definitions and performance of indicating properties based on surface laser scanning and dynamic excitation. Mater Struct. https://doi.org/10.1617/s11527-020-01460-5

Burger N, Glos P (1997) Strength relationships in structural timber subjected to bending and tension. In: Proceedings of CIB-W18 Meeting 30, August 1997, Vancouver, Canada

CEN (2002) Moisture content of a piece of sawn timber-Part 1:Determination by oven dry method. EN 13183-1:2002. European Committee for Standardisation, Brussels, $\mathrm{p} 5$

CEN (2012) Timber structures - structural timber and glued laminated timber-Determination of some physical and mechanical properties. EN408:2010+A1:2012. European Committee for Standardization, Brussels, p 38

CEN (2016a) Structural timber-Strength classes. EN338:2016. European Committee for Standardisation, Brussels, $\mathrm{p} 11$

CEN (2016b) Timber structures-Calculation and verification of characteristic values. EN14358:2016. European Committee for Standardisation, Brussels, p 15

CEN (2018) Structural timber-Determination of characteristic values of mechanical properties and density. EN 384:2016 + A1:2018. In: European Committee for Standardization, Brussels, p 22

Denzler JK (2012) Harmonised tensile strength classes. In: Proceedings of CIB-W18 Meeting 45, August 2012, Växjö, Sweden

Ehrhart T, Fink G, Steiger R, Frangi A (2016) Experimental investigation of tensile strength and stiffness indicators regarding European beech timber. In: Proceedings of the World Conference on Timber Engineering (WCTE 2016), August 22-25, 2016, Vienna, Austria

Ehrhart T, Steiger R, Palma P, Frangi A (2018) Estimation of the tensile strength of European beech timber boards based on density, dynamic modulus of elasticity and local fibre orientation. In: Proceedings of the World Conference on Timber Engineering (WCTE 2018), August 20-23, 2018 Seoul, Rep. of Korea

Fischer C, Vestøl GI, Øvrum A, Høibø OA (2015) Pre-sorting of Norway spruce structural timber using acoustic measurements combined with site-, tree-and log characteristics. Eur J Wood Prod 73:819-828

Fischer C, Vest $\varnothing 1$ GI, Høibø OA (2016) Modelling the variability of density and bending properties of Norway spruce structural timber. Can J for Res. https://doi.org/10.1139/cjfr-2016-0022

Gardiner B, Leban J-M, Auty D, Simpson H (2011) Models for predicting wood density of British-grown Sitka spruce. Forestry 84:119-132

Gil-Moreno D, Ridley-Ellis DJ (2015) Comparing Usefulness of Acoustic Measurements on Standing Trees for Segregation by Timber Stiffness. In: 19th International Nondestructive Testing and Evaluation of Wood Symposium, Rio de Janeiro, Brazil,
2015. USDA Forest Service Forest Products Laboratory (FPL), pp 378-385

Gil-Moreno D, Ridley-Ellis D, McLean P (2016a) Timber properties of noble fir, Norway spruce, western red cedar and western hemlock grown in Great Britain. Forestry Commission

Gil-Moreno D, Ridley-Ellis D, McLean P (2016b) Using the right modulus of elasticity to get the best grades out of softwood timber species in Great Britain. In: Proceedings of the World Conference on Timber Engineering (WCTE 2016), August 22-25, 2016 Vienna, Austria

Gil-Moreno D, O'Ceallaigh C, Ridley-Ellis D, Harte AM (2019a) Use of nondestructive techniques for determination of tension parallel-to-grain properties of spruce. In: 21 st International Nondestructive Testing and Evaluation of Wood Symposium, Freiburg, Germany, 2019. USDA Forest Service Forest Products Laboratory (FPL), pp 233-240

Gil-Moreno D, Ridley-Ellis D, Harte AM (2019b) Timber grading potential of douglas fir in the Republic of Ireland and the UK. Int Wood Prod J 10:64-69. https://doi.org/10.1080/20426445. 2019.1617984

Green DW, Kretschmann DE (1989) A discussion of lumber property relationships in Eurocode 5 Proceedings of CIB W18A Berlin: German Democratic Republic

Hanhijärvi A, Ranta-Maunus A (2008) Development of strength grading of timber using combined measurement techniques: Report of the Combigrade project-phase 2. Technical Report VTT Publications 686 VTT Technical Research Centre of Finland

Hautamäki S, Kilpeläinen H, Verkasalo E (2014) Factors and models for the bending properties of sawn timber from Finland and north-western Russia. Part II: Scots pine. Baltic for 20:142-156

Høibø O, Vestøl GI, Fischer C, Fjeld L, Øvrum A (2013) Bending properties and strength grading of Norway spruce: variation within and between stands. Can J for Res 44:128-135

Kliger IR, Perstorper M, Johansson G (1998) Bending properties of Norway spruce timber. Comparison between fast-and slowgrown stands and influence of radial position of sawn timber. In: Annales des sciences forestières, vol 3. EDP Sciences, pp 349-358

Krajnc L, Farrelly N, Harte AM (2019a) The effect of thinning on mechanical properties of Douglas fir, Norway Spruce, and Sitka Spruce. Ann for Sci 76:3

Krajnc L, Farrelly N, Harte AM (2019b) Evaluating timber quality in larger-diameter standing trees: rethinking the use of acoustic velocity. Holzforschung 73:797-806. https://doi.org/10.1515/ hf-2018-0232

Lavers GM (2002) The strength properties of timber. Department of the Environment, Building Research Establishment, HMSO, London

Llana DF, Short I, Harte AM (2020) Use of non-destructive test methods on Irish hardwood standing trees and small-diameter round timber for prediction of mechanical properties. Ann for Sci 77:62. https://doi.org/10.1007/s13595-020-00957-x

McLean JP, Moore JR, Gardiner BA, Lee SJ, Mochan SJ, Jarvis MC (2016) Variation of radial wood properties from genetically improved Sitka spruce growing in the UK. Forestry 89:109-116

Moore JR (2011) Sitka spruce in Great Britain: wood properties and uses. Forestry Commission Research Report 15. Forestry Commission, Edinburgh. $48 \mathrm{p}$

Moore J, Lyon A, Searles G, Lehneke S, Macdonald E (2008) Scots Pine Timber Quality in North Scotland. Report on the investigation of Mechanical Properties of Structural Timber from three stands Center for Timber Engineering Edinburgh Napier University, Scotland 
Moore JR, Lyon AJ, Lehneke S (2012) Effects of rotation length on the grade recovery and wood properties of Sitka spruce structural timber grown in Great Britain. Ann for Sci 69:353-362

Moore JR, Lyon AJ, Searles GJ, Lehneke SA, Ridley-Ellis DJ (2013) Within-and between-stand variation in selected properties of Sitka spruce sawn timber in the UK: implications for segregation and grade recovery. Ann for Sci 70:403-415

Ni Dhubháin Á, Magner D, Nieuwenhuis M (2006) Juvenile wood in Irish grown Sitka spruce and the impact of rotation length. Ir Forestry 63:26-36

NSAI (2015) IS 127:2015. Structural timber - Visual strength grading - Sawn softwoods with rectangular cross-section. National Standards Authority of Ireland, Dublin, p 28

Ó Fátharta C, Gil-Moreno D, Harte AM (2020) Characterisation of Irish-grown Scots pine timber for structural applications Civil Engineering Research in Ireland 2020 (CERI 2020)

R Core Team (2019) R: A language and environment for statistical computing. R Foundation for Statistical Computing, Vienna, Austria. URL https://www.R-project.org.

Raftery G (2010) The use of advanced composite materials in the flexural reinforcement of low-grade glulam. Doctoral dissertation. National University of Ireland, Galway

Raftery G, Harte AM (2014) Material characterisation of fast-grown plantation spruce. Proc Inst Civ Eng Struct Build 167:380-386

Ranta-Maunus A (2007) Strength of Finnish grown timber. VTT Publications 668. VTT Technical Research Centre of Finland, Espoo, Finland

Ranta-Maunus A, Denzler JK, Stapel P (2011) Strength of European Timber: Part 2. Properties of spruce and pine tested in Gradewood project. VTT Working papers 179. VTT Technical Research Centre of Finland, Espoo, Finland

Ridley-Ellis D, Stapel P, Baño V (2016) Strength grading of sawn timber in Europe: an explanation for engineers and researchers. Eur J Wood Prod 74:291-306

Ridley-Ellis D, Adams S, Lehneke S (2018) Some thresholds for grading British grown spruce to optimised strength classes using longitudinal resonance. In: Proceedings of the World Conference on Timber Engineering (WCTE 2018), August 20-23, 2018 Seoul, Rep. of Korea
Saranpää P (2003) Wood density and growth. In: Barnett JR, Jeronimidis $\mathrm{G}$ (eds) Wood quality and its biological basis. Blackwell Pub, Oxford, pp 87-117

Simic K, Gendvilas V, O'Reilly C, Harte A (2019) Predicting structural timber grade-determining properties using acoustic and density measurements on young Sitka spruce trees and logs. Holzforschung 73:139-149. https://doi.org/10.1515/hf-2018-0073

Stapel P, Denzler J (2010) Influence of the origin on specific properties of European spruce and pine The Future and Quality Control for Wood \& Wood Products. Final Conference of COST Action E53. May 4-7, 2010 Edinburgh, 2010

Stapel P, Van De Kuilen J-WG (2014) Influence of cross-section and knot assessment on the strength of visually graded Norway spruce. Eur J Wood Prod 72:213-227. https://doi.org/10.1007/ s00107-013-0771-7

Steiger R, Arnold M (2009) Strength grading of Norway spruce structural timber: revisiting property relationships used in EN 338 classification system. Wood Sci Technol 43:259-278

Stöd R, Verkasalo E, Heinonen J (2016) Quality and bending properties of sawn timber from commercial thinnings of Scots Pine (Pinus sylvestris L.). Baltic for 22:148-162

Tsehaye A, Buchanan AH, Walker JCF (1997) Characteristic design stresses in tension for radiata pine grown in Canterbury. In: Proceedings of CIB-W18 Meeting 30, August 1997, Vancouver, Canada

Wang X (2013) Acoustic measurements on trees and logs: a review and analysis. Wood Sci Technol 47:965-975

Westermayr M, Stapel P, van de Kuilen JW (2018) Tensile strength and stiffness of low quality beech (Fagus sylvatica) sawn timber. In: Proceedings of the World Conference on Timber Engineering (WCTE 2018), August 20-23, 2018 Seoul, Rep. of Korea

Publisher's Note Springer Nature remains neutral with regard to jurisdictional claims in published maps and institutional affiliations. 